\title{
0 emprego de métodos geofísicos na fase de investigação confirmatória em cemitérios contaminados
}

\author{
Application of geophysical methods in the confirmatory investigation \\ phase in contaminated cemeteries
}

\author{
Robson Willians da Costa Silva \\ Engenheiro Ambiental pela Escola de Engenharia de Piracicaba (EEP). Mestre em Geociências e Meio Ambiente pela Universidade Estadual Paulista "Júlio \\ de Mesquita Filho" (Unesp). Consultor Ambiental. Professor da Faculdade Anhanguera de Piracicaba \\ Walter Malagutti Filho \\ Geólogo pela Unesp Rio Claro. Geofísico do Instituto de Pesquisas Tecnológicas (IPT) na área de Geofísica. Doutorado em Geociências e Meio Ambiente \\ pela Unesp. Livre-docente em Geofísica Aplicada pela Unesp
}

\section{Resumo}

Dentro do gerenciamento de áreas contaminadas, a aplicação de métodos geofísicos, em estudos de área contaminada, constitui uma metodologia confirmatória. Este procedimento - mais precisamente o método da eletrorresistividade por meio das técnicas da sondagem elétrica vertical e imageamento elétrico - foi aplicado no cemitério de Vila Rezende, em Piracicaba, São Paulo, para investigar e mapear a contaminação do cemitério por necrochorume. Os resultados indicam uma profundidade do nível freático entre 3,1 e 5,1 m, com duas direções de fluxo subterrâneo, uma a SW e outra a SE. Tanto as prováveis plumas de contaminação, que têm as mesmas direções de fluxo subterrâneo, quanto as anomalias condutivas verificadas nas seções geoelétricas confirmam as suspeitas de contaminação na área.

Palavras-chave: eletrorresistividade; contaminação; necrochorume; investigação.

\begin{abstract}
Inside of the administration of contaminated areas, the application of geophysical methods, in studies of contaminated area, constitutes a confirmatory methodology. This procedure - more precisely the electrical resistivity method through the techniques of the vertical electric sounding and electrical imaging techniques, was applied at Vila Rezende's cemetery, Piracicaba, São Paulo, Brazil, to investigate and to map the contamination of the cemetery for necrochorume. The results indicate a depth of water table among 3.1 and $5.1 \mathrm{~m}$, with two flow directions, being one to SW and another to SE. So the probable contamination plumes, that have the same directions of underground flow, as for the conductive anomalies verified at the geoelectrics sections confirm the suspicions of contamination in the area
\end{abstract}

Keywords: eletrorresistivity; contamination; necrochorume; investigation.

\section{Introdução}

\section{Aspectos ambientais a serem investigados}

Com a promulgação pelo Conselho Nacional do Meio Ambiente (Conama) da Resolução no 335 de 28 de maio de 2003, os cemitérios são vistos como fontes de contaminação do ambiente, e sua implantação está sujeita ao atendimento dos critérios legais, fazendo-se necessária a implantação de equipamentos de proteção ambiental para salvaguardar o solo e as águas subterrâneas. 
microbiana no solo sob a área de sepultamentos. O autor afirma ainda que, nessas áreas, há aumento da condutividade elétrica, $\mathrm{pH}$, alcalinidade e dureza da solução do solo, devido à presença de compostos de nitrogênio e fósforo e de diversos sais $\left(\mathrm{Cl}^{-}, \mathrm{HCO}_{3}\right.$, $\mathrm{Ca}^{+2}, \mathrm{Na}^{+}$). Ocorre também a presença de óxidos metálicos ( $\mathrm{Ti}, \mathrm{Cr}$, $\mathrm{Cd}, \mathrm{Pb}, \mathrm{Fe}, \mathrm{Mn}, \mathrm{Ni}$, entre outros) lixiviados dos adereços das urnas mortuárias e de patógenos associados a mortes por doenças infectocontagiosas

A norma técnica L1.040 da Companhia de Tecnologia de Saneamento Ambiental (Cetesb) de 1999, Implantação de Cemitérios, e a Resolução Conama n 335 , traçam alguns requisitos técnicos para implantação de novas necrópoles. Partindo desse pressuposto, os principais aspectos dos cemitérios em atividade a serem investigados são os geológico-geotécnicos, hidrogeológicos e ambiental.

\section{Investigação de áreas contaminadas}

Tendo em vista os inúmeros casos de áreas contaminadas divulgados ao público, a Cetesb, com a cooperação técnica do órgão alemão Deutsche Gesellschaft Für Technishe Zusammenarbeit (GTZ), elaboraram, em 2001, o Manual de gerenciamento de áreas contaminadas. Esse manual se tornou referência no âmbito de gerenciamento de áreas contaminadas no Brasil, mas não consta, em seu capítulo 3,

Quadro 1 - Características das atividades passíveis de causarem contaminação encontrada em cemitérios

\begin{tabular}{|c|c|c|}
\hline \multicolumn{2}{|l|}{ Características } & Ocorrência \\
\hline \multicolumn{2}{|c|}{$\begin{array}{l}\text { Existência de processos produtivos que pos- } \\
\text { sam causar contaminação do solo e das águas } \\
\text { subterrâneas }\end{array}$} & $\begin{array}{l}\text { Não ocorrem em } \\
\text { áreas de cemitérios }\end{array}$ \\
\hline \multicolumn{2}{|c|}{$\begin{array}{l}\text { Presença de substâncias que possuem potencial } \\
\text { para causar danos aos bens a proteger via solos } \\
\text { e águas subterrâneas }\end{array}$} & $\begin{array}{l}\text { Pode ocorrer em } \\
\text { áreas de cemitério }\end{array}$ \\
\hline \multicolumn{2}{|c|}{$\begin{array}{l}\text { Atividade industrial ou comercial que apresente } \\
\text { histórico indicando manuseio, armazenamento } \\
\text { ou disposição inadequada de matérias-primas, } \\
\text { produtos e resíduos }\end{array}$} & $\begin{array}{l}\text { Pode ocorrer em } \\
\text { áreas de cemitério }\end{array}$ \\
\hline \multicolumn{2}{|c|}{$\begin{array}{l}\text { Atividade industrial ou comercial que apresente } \\
\text { histórico indicando a ocorrência de acidentes ou } \\
\text { vazamentos }\end{array}$} & $\begin{array}{l}\text { Pode ocorrer em } \\
\text { áreas de cemitério }\end{array}$ \\
\hline \multicolumn{2}{|c|}{$\begin{array}{l}\text { Atividade industrial ou comercial que apresente } \\
\text { histórico de geração de áreas suspeitas de con- } \\
\text { taminação ou de áreas contaminadas }\end{array}$} & $\begin{array}{l}\text { Pode ocorrer em } \\
\text { áreas de cemitério }\end{array}$ \\
\hline \multicolumn{3}{|c|}{ Quadro 2 - Processos e etapas do gerenciamento de áreas contaminadas } \\
\hline Processos & \multicolumn{2}{|c|}{ Etapas do processo } \\
\hline $\begin{array}{l}\text { Identificação de } \\
\text { áreas contaminadas }\end{array}$ & \multicolumn{2}{|c|}{$\begin{array}{l}\text { Definição de áreas de interesse } \\
\text { Identificação de áreas potencialmente conte } \\
\text { Avaliação preliminar } \\
\text { Investigação confirmatória }\end{array}$} \\
\hline $\begin{array}{l}\text { Recuperação de } \\
\text { áreas contaminadas }\end{array}$ & $\begin{array}{r}\text { Investigação d } \\
\text { Avaliação de } \\
\text { Investigação para } \\
\text { Projeto de rem } \\
\text { Remediaç } \\
\text { Monitoram }\end{array}$ & $\begin{array}{l}\text { alhada } \\
\text { risco } \\
\text { emediação } \\
\text { diação } \\
\text { o } \\
\text { nto }\end{array}$ \\
\hline
\end{tabular}

"Identificação de áreas contaminadas", a atividade de sepultamento como passível de causar contaminação.

Uma área contaminada pode ser definida como uma área, local ou terreno onde há comprovadamente poluição ou contaminação causada pela introdução de substâncias ou resíduos que nela tenham sido depositados, acumulados, armazenados, enterrados ou infiltrados de forma planejada, acidental ou até mesmo natural (CETESB, 2001).

O gerenciamento de áreas contaminadas visa minimizar os riscos a que estão sujeitos a população e o meio ambiente, em virtude da existência das mesmas, por meio de um conjunto de medidas que assegurem o conhecimento das características dessas áreas e dos impactos causados por elas, proporcionando os instrumentos necessários à tomada de decisão quanto às formas de intervenção mais adequadas.

A Cetesb (2001) aponta alguns critérios que devem ser levantados para que uma área possa ser considerada como potencialmente contaminada. O Quadro 1 apresenta as características das atividades passíveis de causar contaminação encontrada em cemitérios.

Mesmo que a atividade de sepultamento não se enquadre literalmente como atividade industrial ou comercial, podem ocorrer vazamentos de substâncias passíveis de causar danos ao solo e às águas subterrâneas, visto que, nessa atividade, se manuseiam resíduos biológicos - os cadáveres.

A estratégia para o gerenciamento, proposta pela Cetesb (2001), é constituída por uma série de etapas sequenciais, nas quais as informações obtidas em cada etapa é base para a execução da etapa seguinte. O gerenciamento está dividido basicamente em dois processos, subdivididos nas etapas, conforme visto no Quadro 2. A Figura 1 apresenta o sequenciamento do processo de identificação de áreas contaminadas.

A etapa de definição da área de interesse marca o início do gerenciamento das áreas contaminadas (ACs). São definidos os objetivos principais a ser alcançados e a área do gerenciamento, considerando o solo e as águas subterrâneas como os principais bens a proteger.

A identificação das áreas potencialmente contaminadas (APs) é realizada coletando-se os dados necessários por meio das técnicas de levantamento de dados existentes, de investigações e por observação do histórico.

A avaliação preliminar consiste na elaboração de um diagnóstico inicial das APs, com um levantamento de informações existentes e

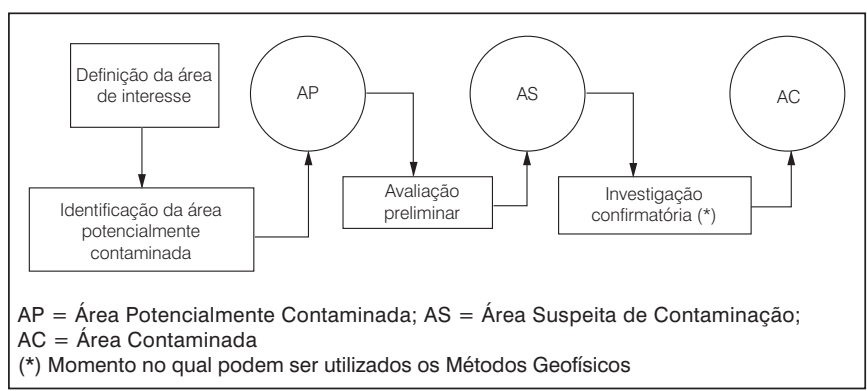

Figura 1 - Processo de identificação de áreas contaminadas 
de informações coletadas em inspeções de reconhecimento do meio físico, observando os fatos que levem à confirmação da contaminação na área e ao estabelecimento do modelo conceitual de contaminação, além da adoção de medidas emergências no local, classificando-o como área suspeita de contaminação (AS) ou não.

A etapa de investigação confirmatória encerra o processo de identificação de áreas contaminadas e tem como objetivo principal confirmar ou não a existência de contaminação nas áreas suspeitas, identificadas na etapa de AP. Nessa etapa, as áreas anteriormente classificadas como ASs são avaliadas, por meio de métodos diretos e indiretos de investigação do meio físico, visando à comprovação da presença de contaminação e possibilitando a classificação das mesmas como ACs.

\section{Métodos geofísicos na investigação de contaminação de cemitérios}

Os métodos geofísicos (Figura 2) são constituídos por técnicas indiretas de rastreamento em subsuperfície, não invasivos e, portanto, não destrutivos. São empregados em estudos hidrogeológicos, para a determinação da profundidade da zona saturada, identificação do sentido de fluxo da água subterrânea, no mapeamento em subsuperfície de pluma de contaminante, de falhas e fraturas, entre outros.

$\mathrm{Na}$ etapa de investigação confirmatória, os métodos geofísicos são utilizados para localizar os pontos de amostragem mais adequados, determinando anomalias que representam os locais com maiores concentrações de contaminantes (hot spots).

Dessa forma, são avaliadas as condições geológicas locais por meio dos contrastes das propriedades físicas dos materiais de subsuperfície, como condutividade ou resistividade elétrica, permissividade dielétrica, magnetismo, densidade etc., podendo ter como origem as diferenciações litológicas e outras heterogeneidades naturais ou não.

Em cemitérios, a aplicação de métodos geofísicos na caracterização subsuperficial, apresenta inúmeras vantagens técnico-econômicas, principalmente por serem técnicas investigativas indiretas, não causando dano às construções presentes, como columbários, jazigos, lápides e outros, e com um custo relativamente baixo em comparação com outras técnicas de prospecção, além da rapidez na aquisição dos dados. Os levantamentos geofísicos propiciam a execução de perfis contínuos, possibilitando a identificação com maior precisão das variações laterais decorrentes das mudanças litológicas ou originadas pela presença da contaminação subterrânea.

Dessa forma, este trabalho teve como objetivo investigar a contaminação em um cemitério por meio do método geofísico da eletrorresistividade, correspondendo à fase de investigação confirmatória, visto que o cemitério no qual o trabalho foi executado apresenta condições hidrogeoambientais favoráveis à contaminação do meio, dados históricos de vazamento de necrochorume dos jazigos e saponificação dos cadáveres

\section{Descrição da área de estudo}

Em operação desde 15 de setembro de 1976, com uma área de $75.324,48 \mathrm{~m}^{2}$, com mais de 16.500 pessoas sepultadas e média de dois sepultamentos por dia, o cemitério público de Vila Rezende esta localizado na zona norte do município de Piracicaba (47³9'07'W; $22^{\circ} 41^{\prime} 37^{\prime \prime S}$ ) a $170 \mathrm{~km}$ da capital paulista (Figura 3).

O cemitério está dividido em 11 quadras, predominando, até 1988, o sepultamento por inumação, em covas simples, cuja profundidade varia de 1,1 a 1,6 m, com simples recobrimento de solo, nas quadras 3, 5, 6, 7, 9, 10 e 11. Em 1993, o processo de sepultamento passou a ser por jazigos subterrâneos em alvenaria. Devido às condições hidrogeoambientais desfavoráveis ao sepultamento subterrâneo e também às legislações federais e estaduais, a partir de 1999 foi iniciado o processo de sepultamento em jazigos acima do nível do terreno. A resolução Conama n 335 enfatiza que o nível freático deve distar 1,5 m da base da sepultura. Assim, a ocupação do cemitério iniciou-se nas quadras 1 e 11 e, sucessivamente, ao longo de 30 anos, nas quadras $7,6,10,9,5,2,3,4$ e 8

A geologia da área é caracterizada por siltitos argilosos da Formação Corumbataí, principalmente nas quadras 1, 4 e 8 . A condutividade hidráulica média dessa formação é de $6,5 \cdot 10^{-7} \mathrm{~cm} / \mathrm{s}$.

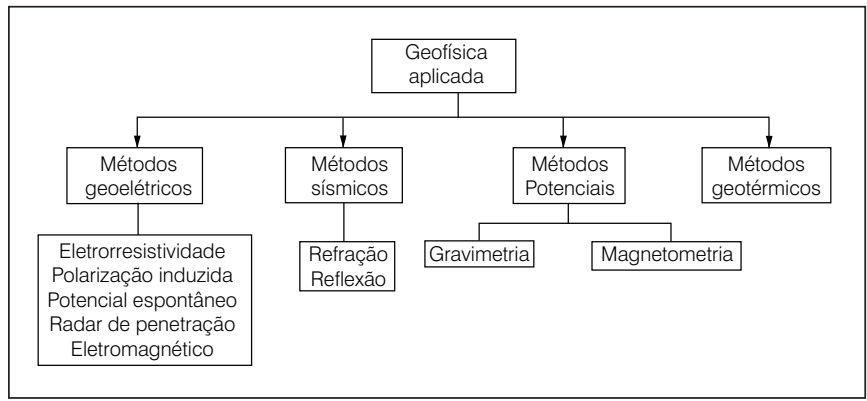

Figura 2 - Métodos geofísicos de prospecção

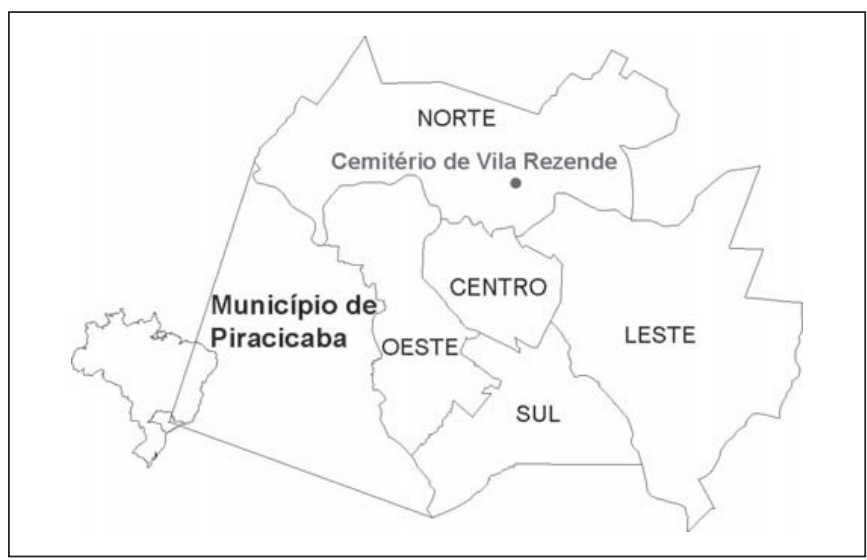

Figura 3 - Localização esquemática do cemitério de Vila Rezende 


\section{Metodologia}

O método da eletrorresistividade consiste em injetar corrente elétrica, por meio de contatos diretos com o solo, e medir a diferença de potencial elétrico, por eletrodos metálicos aterrados ao solo. Quando os valores da corrente e do potencial são registrados, é possível calcular a resistividade dos materiais em subsuperfície.

As técnicas mais utilizadas são a sondagem elétrica vertical (SEV), que investiga as heterogeneidades verticais das resistividades, e o imageamento elétrico (IE) que investiga as heterogeneidades horizontais e verticais das resistividades.

Os arranjos eletródicos mais utilizados pelo método da eletrorresistividade, utilizando as técnicas de SEV e IE, são: gradiente, dipolo-dipolo, pólo-dipolo, Schlumberger e Wenner (WARD, 1990). A escolha do arranjo de superfície dos eletrodos depende dos propósitos do levantamento, da situação geológica e do tipo e da qualidade de informações desejadas. Neste trabalho, empregaram-se as técnicas da SEV com o arranjo Schlumberger e o IE 2D com o arranjo dipolo-dipolo.

O arranjo de campo Schlumberger (Figura 4) é o mais utilizado em SEVs, devido à qualidade das curvas de campo, facilidade e rapidez na execução do ensaio e menor suscetibilidade às variações laterais de resistividade e ruídos, como correntes naturais no subsolo, linhas de alta tensão etc. Neste arranjo, os eletrodos de corrente $\mathrm{AB}$ apresentam uma separação crescente, e os eletrodos de potencial MN permanecem fixos - a uma distância $\leq \mathrm{AB} / 5$, durante o desenvolvimento do ensaio. O objetivo básico nesse arranjo é fazer com que a distância que separa os eletrodos $\mathrm{M}$ e $\mathrm{N}$ tenda a 0 em relação à distância crescente entre A e B. Devido aos procedimentos de campo descritos, o erro produzido por esse tipo de arranjo pode ser considerado insignificante (ORELLANA, 1972). A resistividade utilizando esse arranjo é dada pela Equação 1:

$$
\rho=\frac{\Delta V}{I}\left(\pi \frac{A M \cdot A N}{M N}\right)
$$

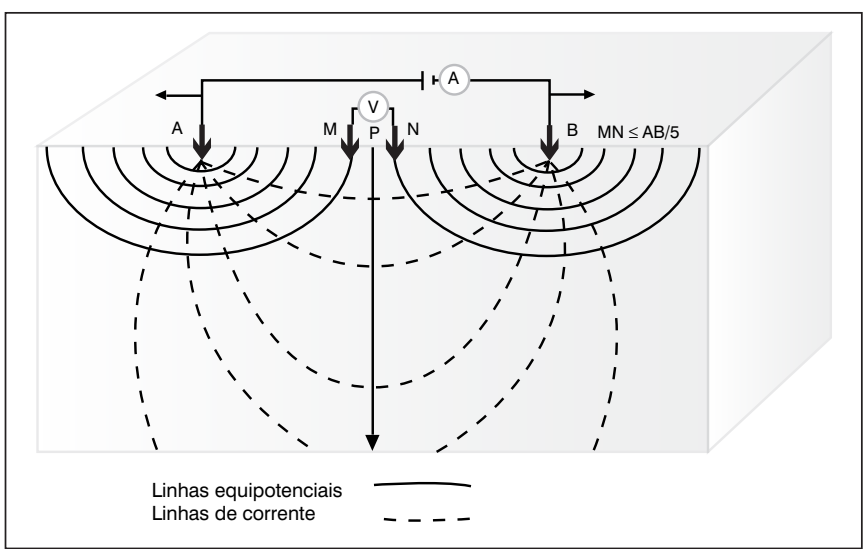

Figura 4 - Arranjo Schlumberger
O arranjo dipolo-dipolo (Figura 5) é um dos mais utilizados na investigação de contaminantes, pela precisão nos resultados e rapidez na execução em campo. Apresenta melhor resolução, anomalias mais intensas, considerando relações verticais (WARD, 1990). Neste arranjo, a configuração é de dois eletrodos, A e B, de emissão de corrente e de dois eletrodos, $\mathrm{M}$ e N, de potencial com igual abertura ' $\mathrm{x}$ ', estando os eletrodos dispostos em um mesmo alinhamento. O ponto de atribuição do valor calculado é a intersecção das linhas que partem do centro de $\mathrm{AB}$ e $\mathrm{MN}$, com ângulo de $45^{\circ}$. Observa-se, na Figura 5, que o espaçamento R varia nos múltiplos de abertura do dipolo, na forma $\mathrm{x}(\mathrm{n}+1)$, onde $\mathrm{x}=1,2,3, \ldots$ é o número de dipolos MN. Assim, o nível teórico de investigação progressivamente cresce com o crescimento de R, que teoricamente corresponde a $\mathrm{x}(\mathrm{n}+1) / 2$.

A resistividade utilizando o arranjo dipolo-dipolo é calculada pela Equação 2:

$$
\rho=\frac{\Delta V}{I} 2 \pi \frac{1}{\left(\frac{1}{n}-\frac{2}{n+1}+\frac{1}{n+2}\right)}
$$

Para estabelecer o modelo geoelétrico e, posteriormente, a elaboração do mapa potenciométrico da área do cemitério, foram realizadas 16 SEVs, com espaçamento dos eletrodos AB de até 200 m, em setembro de 2006. As SEVs foram distribuídas em toda área de estudo (Figura 6), sendo executados sete ensaios na área interna do cemitério (SEV: 7, 8, 9, 10, 11, 12 e 13), e nove ensaios na área externa do cemitério (SEV: 1, 2, 3, 4, 5, 6, 14, 15 e 16). O aparelho utilizado foi o resistivímetro Bison, modelo 2390 da Bison Instruments Inc. O processamento das SEVs visando à obtenção do modelo geoelétrico foi realizado no software IX1D v.3 da Interpex Limited, utilizando tanto o método direto como inverso. No método direto, admitiu-se um modelo inicial, baseado no conhecimento prévio da geologia local. O algoritmo do software calculou a curva de resistividade e, após um ajuste razoável, o modelo foi refinado por meio da inversão, com base

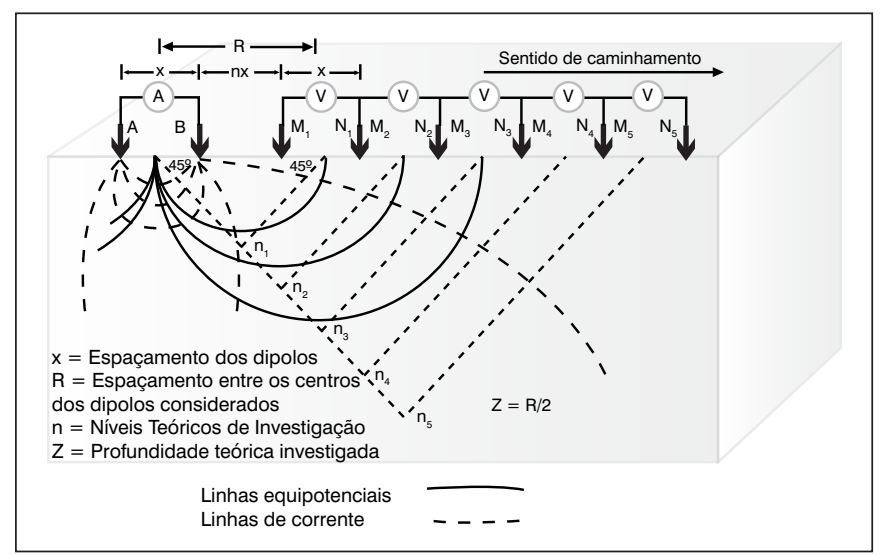

Figura 5 - Arranjo dipolo-dipolo 
no método dos mínimos quadrados, que busca uma convergência da curva teórica para a curva de campo.

Após obtidas as profundidades dos níveis freáticos nos locais das SEVs e suas coordenadas UTM, foi possível elaborar o mapa potenciométrico da área, utilizando o software Surfer v.8 da Golden Software, com a interpolação geoestatística de mínima curvatura. Esse método de interpolação geoestatística é um método suavizador, sendo o que melhor representa as linhas equipotencias.

Para investigação e mapeamento geoelétrico do cemitério, foram executadas 12 linhas de IEs (Figura 6), em fevereiro de 2007, com comprimento de até $390 \mathrm{~m}$, espaçamento de $10 \mathrm{~m}$ entre eletrodos, 5 níveis de investigação, resultando numa profundidade teórica de $15 \mathrm{~m}$, por meio do resistivímetro Terrameter SAS 4000 da Abem Instruments. Os dados foram processados no software RES2DINV, de autoria de Loke (2004), que executa um imageamento 2D do terreno, empregando a técnica da inversão por meio do método dos mínimos quadrados. Os resultados da inversão pelo RES2DINV foram exportados na forma de arquivos XYZ e interpolados por krigagem simples pelo Surfer, para elaborar as seções geoelétricas.

Para gerar os mapas 3D de resistividade elétrica dos 5 níveis de investigação, foi realizada uma análise geoestatística de 274 dados por nível pelo software Variowin 2.21, de autoria de Pannatier (1996). O modelo variográfico foi exportado para o software Surfer, para a realização da interpolação pelo método da krigagem ordinária.

\section{Resultados e discussão}

\section{SEV}

O modelo geoelétrico da área interna do cemitério (Tabela 1) apresenta uma heterogeneidade de valores de resistividade entre 10 e 2.960 $\Omega$.m, sendo os níveis mais condutivos interpretados como provável contaminação por necrochorume e os mais resistivos, como horizontes areno-argilosos, aterro com sedimentos arenosos, cascalho de calcário, resíduos de construção e demolição moídos e reciclados, e tubulações e galerias de drenagem superficial. As curvas apresentam padronização da segunda parte em diante, em profundidade e resistividade a partir de $4 \mathrm{~m}$ e $180 \Omega$.m, respectivamente, interpretado como siltitos argilosos da Formação Corumbataí. No entanto, em algumas SEVs, o seu último nível (a partir de $18 \mathrm{~m}$ ) apresentou resistividade 15 vezes maior em relação ao nível geoelétrico anterior, podendo ser correlacionadas com o diabásio. A Figura 7 apresenta curva típica (SEV-7) da área interna, com sua respectiva correspondência hidrogeológica.

Devido ao caráter arenoso das camadas superficiais (aterro) do cemitério, os líquidos provenientes da decomposição dos corpos necrochorume - podem fluir perfeitamente. Já nas camadas mais profundas, os sedimentos apresentam condições fisico-químicas, como textura argilosa e baixa condutividade hidráulica, que são desfavoráveis para percolação do necrochorume - embora isso facilite o fenômeno de saponificação dos cadáveres.

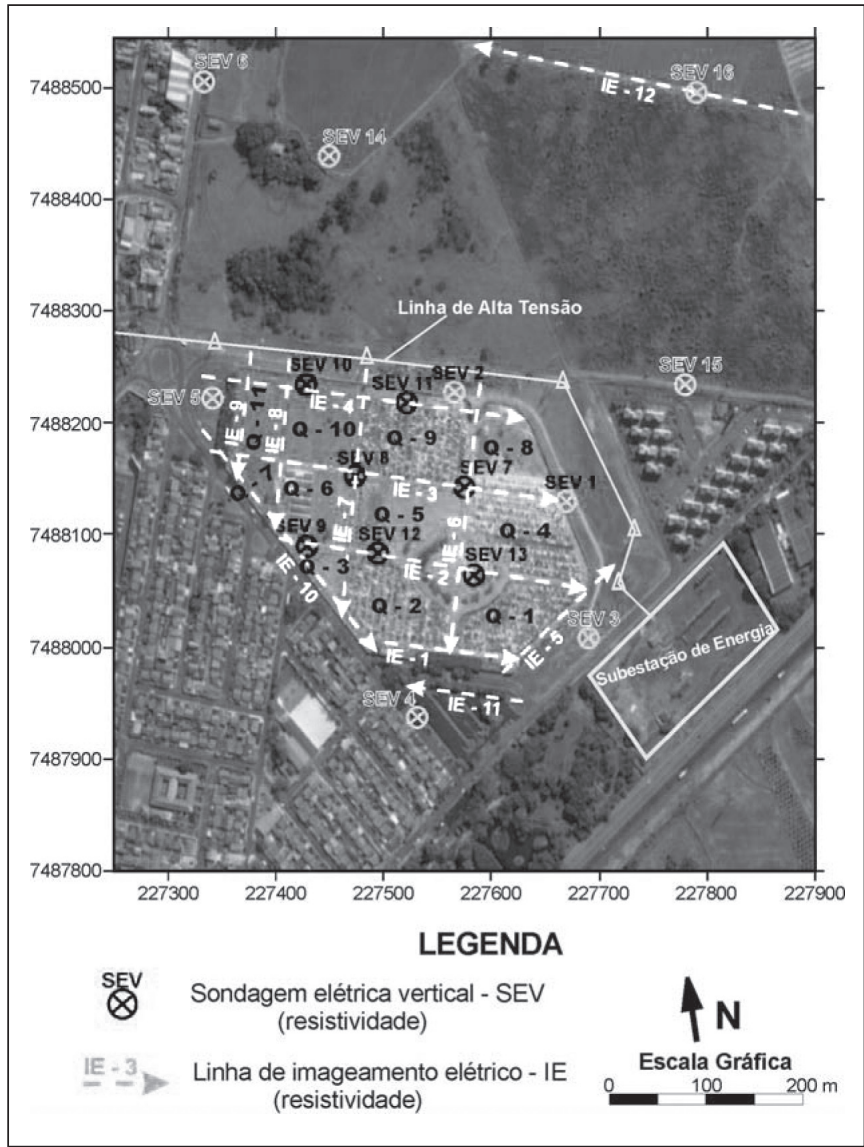

Figura 6 - Localização dos ensaios geoelétricos realizados na área de estudo

Tabela 1 - Modelo geoelétrico proposto para a área interna do cemitério

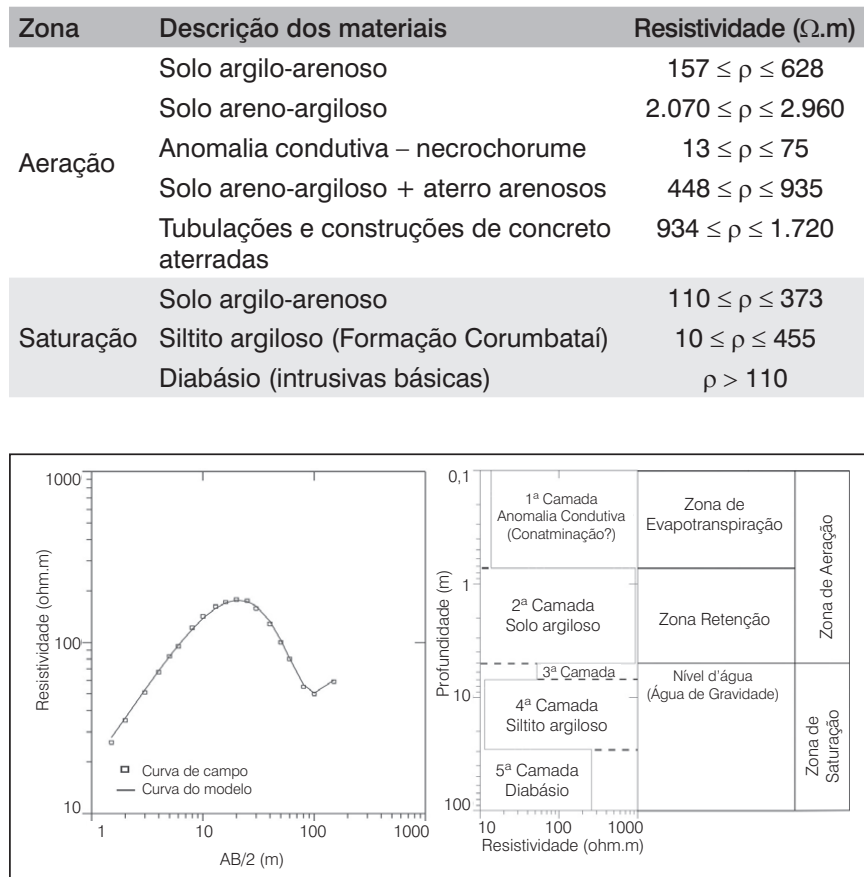

Figura 7 - Curva típica da área interna e sua caracterização hidrogeológica 
O modelo geoelétrico da área externa do cemitério (Tabela 2) apresenta diversos tipos de materiais geológicos em subsuperfície. As SEVs a leste apresentaram estratos geoelétricos característicos da Formação Corumbataí, e as SEVs a oeste e ao norte do cemitério apresentaram estratos geoelétricos característicos da Formação Corumbataí e diabásio na profundidade acima de 15 m. A anomalia condutiva na zona saturada é referente a SEV-3 que se localiza a montante da quadra 1 e 4 . A Figura 8 apresenta curva típica da área interna com sua respectiva correspondência hidrogeológica.

Por meio das profundidades da zona saturada obtidas pelas SEVs, obteve-se o mapa potenciométrico da área do cemitério de Vila Rezende e seu entorno (Figura 9). Notam-se dois sentidos de fluxo subterrâneo, um para SW e outro para SE, e com profundidade do nível freático variando em época de estiagem entre 3 e 5,5 m. Nas quadras 1, 4, 8 e 9, as profundidades variam entre 3 e $4 \mathrm{~m}$.

\section{IE}

As seções de IE-1, 2, 3 (Figura 10) apresentam altos valores de resistividade aparente entre 700 e $2.600 \Omega$.m associados às tubulações e outras construções de concreto para drenagem superficial aterradas no local. Os valores de resistividade entre 150 e 700 $\Omega$.m correlacionam-se com uma camada de solo argilo-arenoso e o intervalo de resistividade, de 50 a $150 \Omega$.m, correlaciona-se aos siltitos argilosos da Formação Corumbataí. No entanto, nessas seções, ocorrem baixos valores de resistividade aparente (< de 75 $\Omega$.m) próximo à superfície, acima do nível freático, correspondendo a uma anomalia condutiva, proveniente da influência do vazamento de necrochorume dos jazigos a montante. Essas anomalias ficam evidenciadas na seção de IE-1 entre 55 e $68 \mathrm{~m}$ a jusante da quadra 2 e a partir de $110 \mathrm{~m}$ a jusante da quadra 1 . Na seção de IE-2 as anomalias condutivas encontram-se entre 70 e $145 \mathrm{~m}$ a jusante das quadras 6 e 5 e a partir de 200 m no canteiro central e a jusante da quadra 4. Já no IE-3 as anomalias encontram-se entre 155 e $225 \mathrm{~m}$ e a partir de $195 \mathrm{~m}$ a jusante das quadras 9 e 8 , respectivamente.

Observando as seções de IE-1, 2 e 3, encontram-se valores de resistividade menores, a partir do terço final, mais precisamente a jusante das quadras 1, 4 e 8 , onde os solos são mais argilosos e, portanto, mais condutivos. Por meio das informações das SEV-7 e 1 e por informações dos funcionários do cemitério, foi observado que o nível freático nessa área é mais raso, principalmente nos períodos de chuva, podendo ocorrer afloramento próximo ao muro. Sendo assim, nessa área, a zona de aeração é menos espessa, pois é, portanto, mais vulnerável à contaminação, uma vez que a zona não-saturada desempenha um papel de filtro dos contaminantes biológicos.
Tabela 2 - Modelo geoelétrico proposto para a área externa do cemitério.

\begin{tabular}{llc}
\hline Zona & Descrição dos materiais & Resistividade $(\Omega . m)$ \\
\multirow{4}{*}{ Aeração } & Solo argilo-siltoso & $28 \leq \rho \leq 220$ \\
& Solo argilo-arenoso & $138 \leq \rho \leq 1.093$ \\
& Solo areno-argiloso & $1.100 \leq \rho \leq 2.960$ \\
\cline { 2 - 2 } Saturação & Siltito argiloso (Formação Corumbataí) & $24 \leq \rho \leq 398$ \\
& Anomalia condutiva - necrochorume & $\rho<10$ \\
& Siltito argiloso (Formação Corumbataí) & $10 \leq \rho \leq 53$ \\
& Diabásio (intrusivas básicas) & $\rho>105$
\end{tabular}

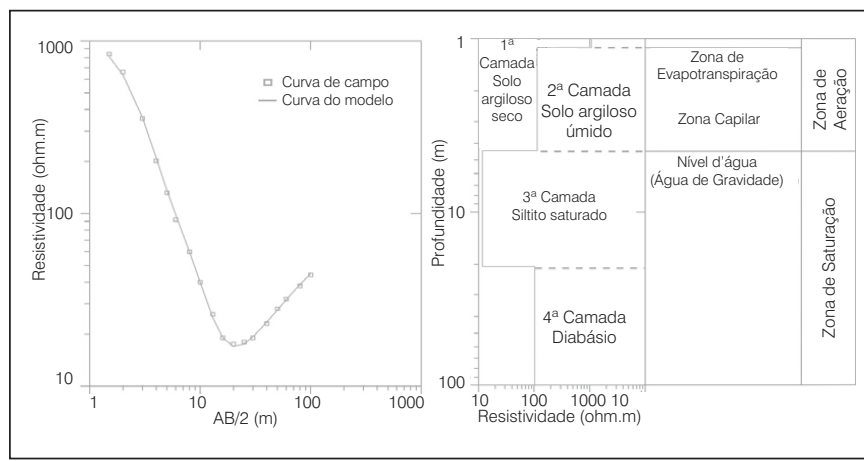

Figura 8 - Curva típica da área externa e sua caracterização hidrogeológica

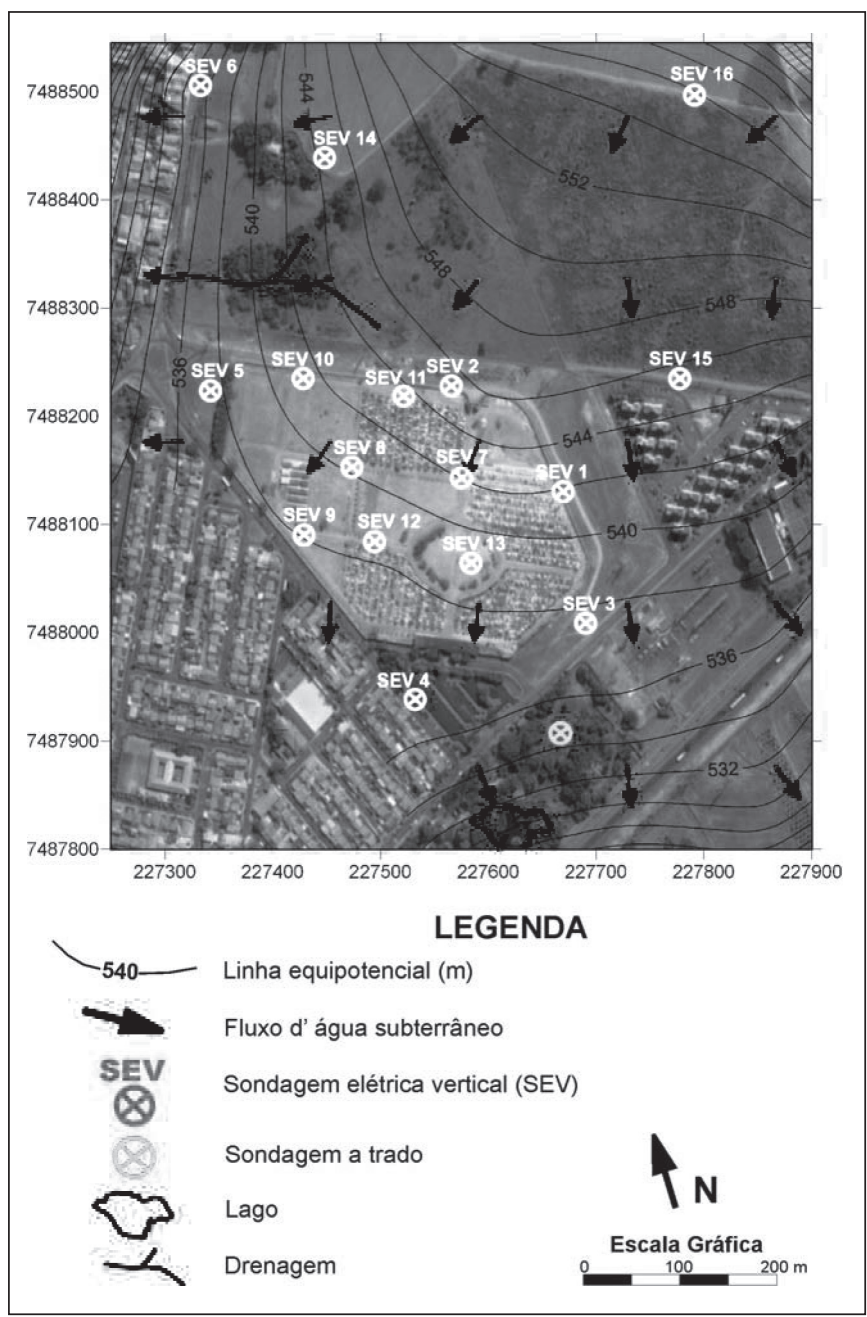

Figura 9 - Mapa potenciométrico da área do cemitério de Vila Rezende 


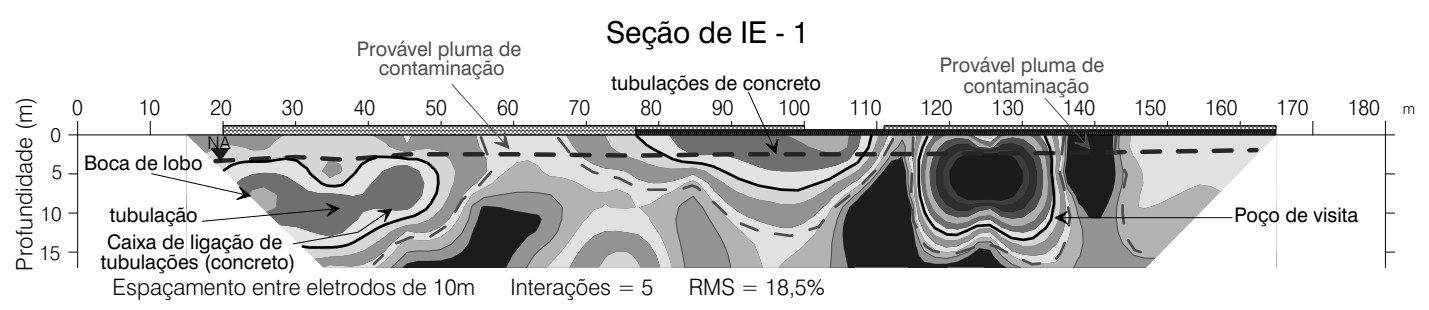

Seção de IE - 2

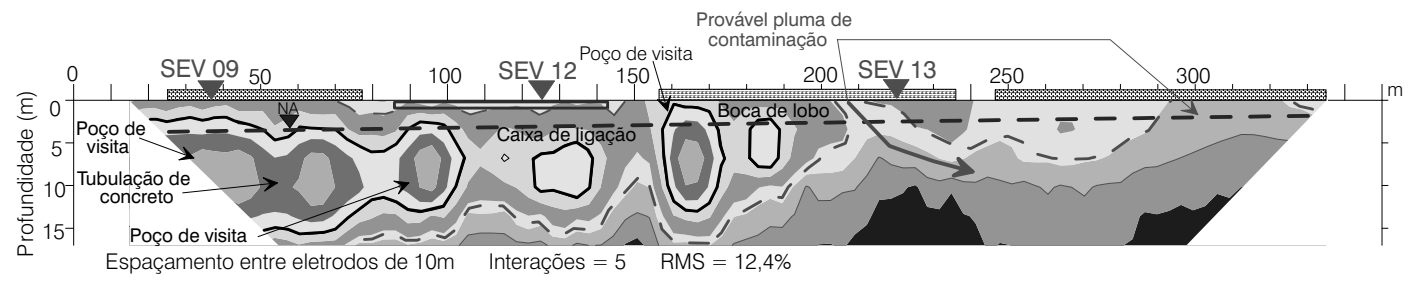

Seção de IE - 3

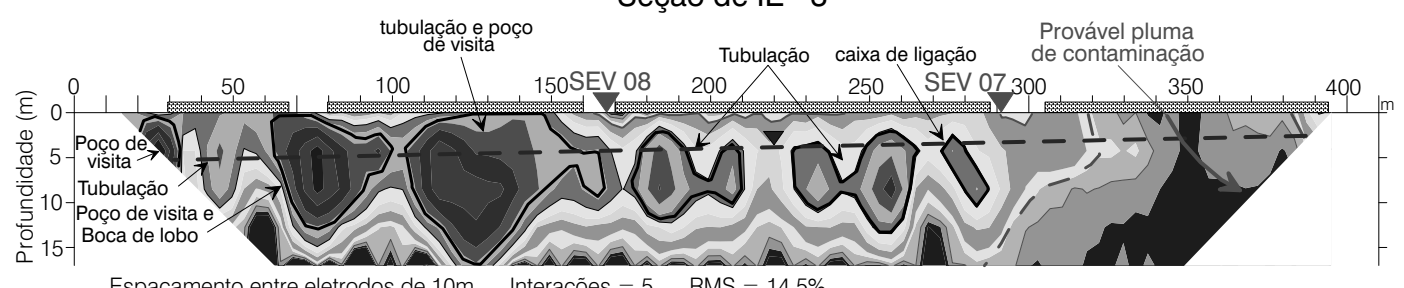

Espaçamento entre eletrodos de $10 \mathrm{~m} \quad$ Interações $=5 \quad \mathrm{RMS}=14,5 \%$

Seção de IE - 5

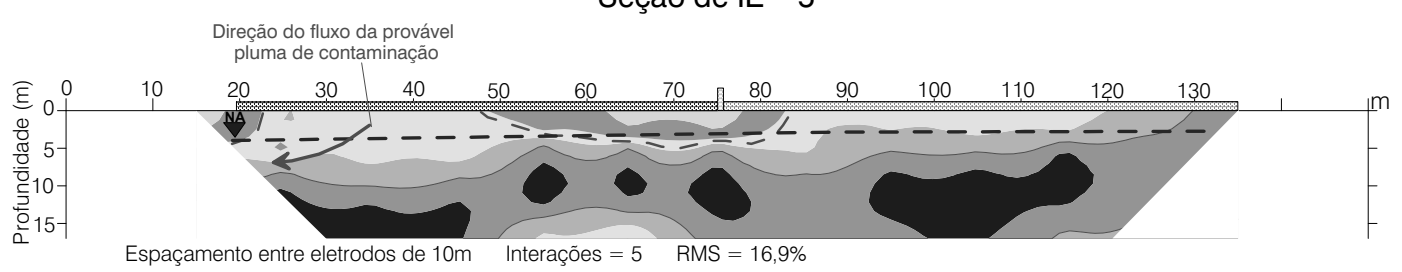

Seção de IE - 11

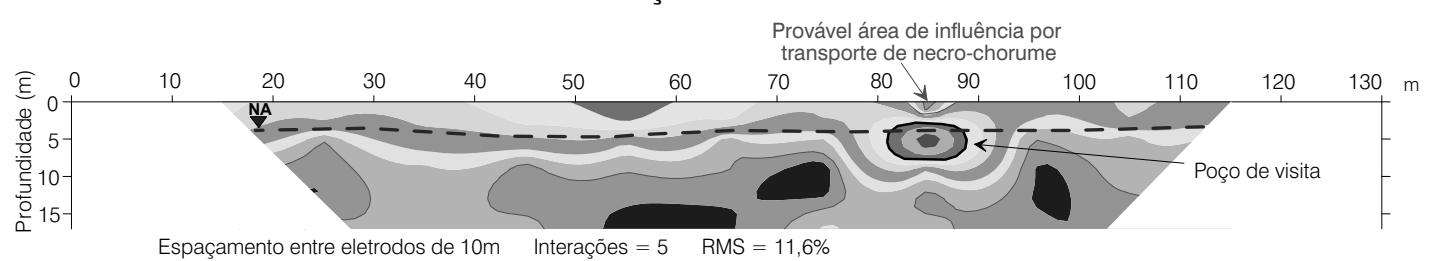

Seção de IE - 12

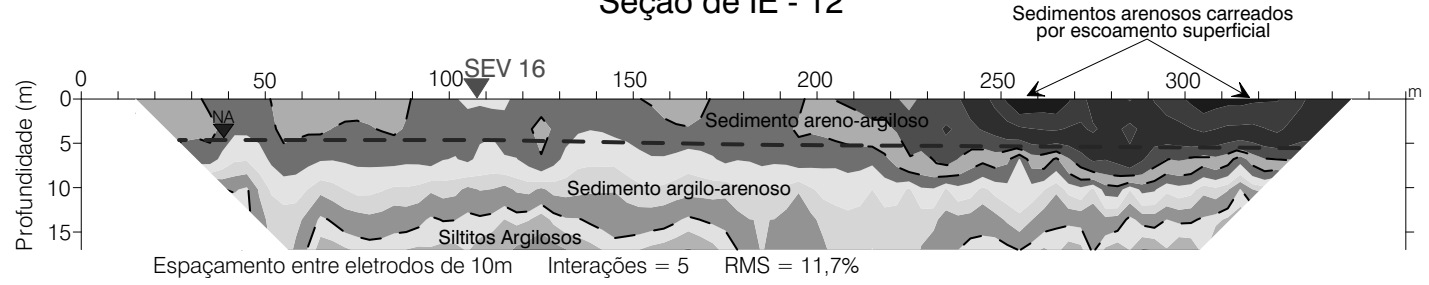

Espaçamento entre eletrodos de 10m Interações $=5 \quad \mathrm{RMS}=11,7 \%$

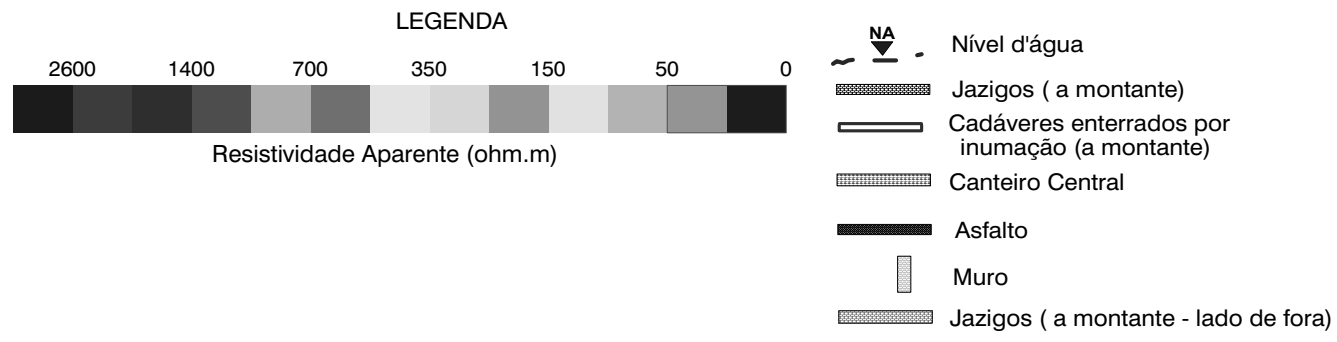

Figura 10 - Seções geoelétricas: linhas de IE-1, 2, 3, 5, 11 e 12 
Na seção de IE-5, ocorrem baixos valores de resistividade aparente (abaixo de $75 \Omega$.m) próximo à superfície, acima do nível freático, correspondendo a uma anomalia condutiva proveniente da influência do vazamento de necrochorume dos jazigos a montante.

A parte final das seções de IE-2, 3 e toda a seção 5, mais precisamente a jusante das quadras 1,4 e 8 , apresentaram, em todas as camadas, resistividades aparentes inferiores a 150 S.m. Essa área, além de apresentar baixo nível freático, é a de maior intensidade de

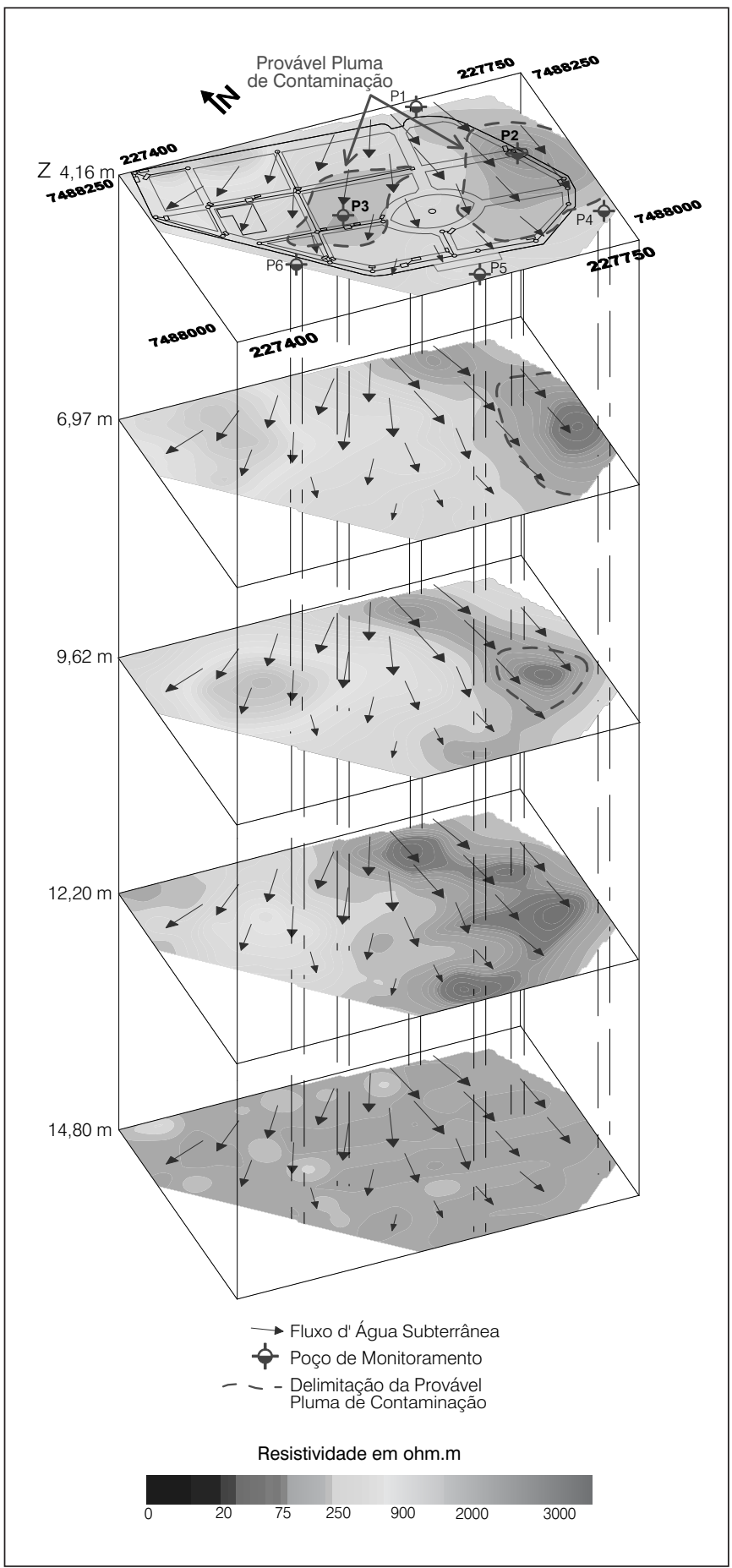

Figura 11 - Mapa 3D de resistividade elétrica para os cinco níveis de investigação sepultamentos, havendo assim uma constante renovação da fonte contaminadora. Dent (1995), em um cemitério na Austrália, e Matos (2001), no cemitério Vila Nova Cachoeirinha, em São Paulo, constataram que há aumento da condutividade elétrica no lençol freático próximos de sepultamentos recentes. Migliorini (1994), no cemitério Vila Formosa, em São Paulo, e Almeida e Macêdo (2005), em cinco cemitérios na cidade de Juiz de Fora, Minas Gerais, constataram aumento da condutividade elétrica no lençol freático por meio de altas concentrações de íons maiores, principalmente o cloreto e compostos nitrogenados.

Na superfície das quadras 1, 4 e 8, há presença de jazigos acima do nível do terreno com até quatro gavetas, preparados para alojar diversos cadáveres num mesmo local ao longo dos anos, após o período de exumação. Desta forma, a principal fonte de contaminação são esses tipos de jazigos, nos quais continuamente ocorrem sepultamentos e, consequentemente, renovação das fontes contaminadoras.

Na seção IE-11, que está localizada na área externa do cemitério - aproximadamente $40 \mathrm{~m}$ da quadra 1 , observa-se que as faixas de baixa resistividade estão abaixo de $7 \mathrm{~m}$ de profundidade, em zona saturada, a jusante do fluxo no cemitério, podendo ter influência do necrochorume. Romero (1970) apud Pacheco (1986) afirma que o percurso de contaminantes biológicos em sedimentos com textura fina, que é o caso do necrochorume e o aquífero presente no cemitério, pode chegar a $30 \mathrm{~m}$.

A seção IE-12 foi realizada a aproximadamente $320 \mathrm{~m}$ a NW e a montante da área cemitério, servindo assim como uma linha de comparação (background). Foi realizada a essa distância, devido à inexistência de uma área a montante próxima ao cemitério, com dimensões suficientes para realização do ensaio, e que fosse isenta de interferências causadas pela linha de alta tensão presente no entorno do cemitério. Segundo Orellana (1972), um valor anômalo deve diminuir ou ultrapassar em pelo menos duas ou três vezes o valor de background.

Os altos valores de resistividade aparente que ocorrem na seção IE-12 demonstraram que essa área é isenta de anomalias condutivas proveniente de contaminação por necrochorume. Os valores de resistividades entre 700 e $2.600 \Omega$.m relacionam-se ao solo argiloarenoso, areno-argiloso e aos sedimentos arenosos carreados por escoamento superficial e depositados em curvas de nível do local. Os valores de resistividade entre 150 e $700 \Omega$.m correlacionam-se com uma camada de solo argilo-arenosa saturados. Os valores de resis-

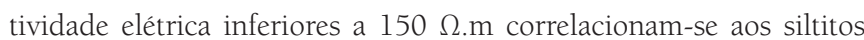
argilosos da Formação Corumbataí.

A Figura 11 apresenta o mapa 3D de resistividade elétrica para os cinco níveis de investigação que corresponde a uma profundidade de 4,16 a 14,8 m, segundo o modelo do software RES2DINV.

Observam-se, no mapa, duas prováveis plumas de contaminação no primeiro nível de investigação: uma na direção SW e outra a SE, ambas seguindo a direção do fluxo subterrâneo. A provável pluma a 
SW inicia-se sob a quadra 9 e se estende sob as quadras 5, 6, 3 e 2. As anomalias condutivas podem ser também observadas nas seções geoelétricas das linhas de IE-2, 3 e 7 e nos primeiros níveis geoelétricos das SEVs-7, 8 e 12. Já a provável pluma a SE inicia-se sob a quadra 8 e se estende sob as quadras 4, 1, uma parte do canteiro central e fora dos limites do cemitério. Essas anomalias condutivas são observadas nas seções geoelétricas IE-2, 3 e 5.

No mapa do segundo nível de investigação, há uma provável pluma de contaminação na direção SE, provavelmente a extensão da pluma do nível anterior. Essa pluma inicia-se entre a quadra 8 e 4 , se estende até a quadra 1 e também para a área externa do cemitério.

Há uma provável pluma de contaminação na direção SE no terceiro nível de investigação, iniciando-se sob a quadra 4 e se estendendo sob a quadra 1 e fora dos limites do cemitério.

Observa-se, no mapa para o quarto nível de investigação, que, na maioria das quadras, ocorrem valores baixos de resistividade elétrica, que representam os materiais geológicos saturados da Formação Corumbataí. Já o mapa para o quinto nível apresenta valores baixos de resistividade elétrica em toda a área do cemitério, representando os materiais geológicos saturados da Formação Corumbataí.

Após a identificação das prováveis plumas por meio do mapeamento das mesmas, recomenda-se a instalação de seis poços de monitoramento nos locais designados na Figura 11. O primeiro poço (P1) teria como função o controle da água subterrânea em meio não contaminado a montante do fluxo da água subterrânea, na área do cemitério (background); os poços P2 e P3 se localizariam onde se mapearam pela investigação geoelétrica as prováveis plumas de contaminação; os poços P4, P5 e P6 seriam localizados na área externa do cemitério, a jusante na direção do fluxo subterrâneo e das plumas de contaminação.

\section{Conclusões}

O modelo geoelétrico da área externa ao cemitério apresenta uma camada de 4 m de material argilo-siltoso a SE do cemitério e material argilo-arenoso e areno-argiloso a NE, NW e SW. Na área interna, há uma camada pouco espessa de aterro de sedimentos arenosos. Abaixo da camada de aterro, ocorre um material argilo-siltoso nas quadras a leste do cemitério, e argilo-arenoso nas quadras a oeste do cemitério, em ambas as direções, provenientes dos siltitos argilosos da Formação Corumbataí.

Há dois sentidos de fluxo subterrâneo no cemitério, um sentido a SW e o outro a SE, com profundidade do nível freático no período de estiagem, entre 3,1 e 5,1 m.

O cemitério apresenta condições desfavoráveis na percolação do necrochorume devido à predominância de um material argiloso. No entanto, existem condições favoráveis para a ocorrência do fenômeno conservativo de saponificação e a expansão em baixa profundidade da pluma de contaminante, devido à baixa profundidade do nível freático.

Pelas diversas anomalias condutivas em zona não saturada e por duas prováveis plumas de contaminação, uma na direção SW e outra a SE - a última se prolongando em grande profundidade - o cemitério de Vila Rezende passa de uma área suspeitamente contaminada para uma área confirmadamente contaminada por necrochorume.

\section{Agradecimentos}

À Coordenação de Aperfeiçoamento de Pessoal de Nível Superior (Capes) pelo auxílio na execução deste trabalho.

\section{Referências}

ALMEIDA, A.M.; MACÊDO, J.A.B. Parâmetros físico-químicos de caracterização da contaminação do lençol freático por necrochorume. In: SEMINÁRIO DE GESTÃO AMBIENTAL - UM CONVITE A INTERDISCIPLINARIEDADE, Anais..., Juiz de Fora: Instituto Viana Junior, 2005.

BRASIL. Conselho Nacional do Meio Ambiente. Resolução no 335, de 3 de abril de 2003. Dispõe sobre o licenciamento ambiental de cemitérios. 2003. Disponível em: <http://www.aguaseaguas.ufjf.br/ RESOLUCAO\%20conama335\%20CEMITERIOS.pdf>. Acesso em: 13 set. 2006

COMPANHIA DE TECNOLOGIA DE SANEAMENTO AMBIENTAL. Manual de gerenciamento de áreas contaminadas. Programa Cetesb/GTZ. São Paulo, 2001
Norma L1.040: Implantação de cemitérios. São Paulo, 1999.

DENT, B.B. Hydrogeological studies at botany cemetery. M.Sc. Project Report. Sydney: University of Technology of Sydney, 1995.

GOLDEN SOFTWARE. Surfer version 8.0: surface mapping system. Colorado, USA: Golden Software, 2002. 1 CD-Rom.

INTERPEX LIMITED. IX1D v.2.0: Instruction manual. Colorado, USA: Golden, 2008. Disponível em: <http://www.interpex.com/ix1d/ix1d version.htm>. Acesso em: 21 mai. 2008

LOKE, M.H. RES2DINV ver. 3.54 for Windows 98/Me/2000/NT/XP: Rapid 2D Resistivity \& IP Inversion using the least-squares method. Penang, Malaysia: Geotomo Software, 2004. Disponível em: <http://www. 
geophysik.tu-freiberg.de/assets/media/Personal/rub/Praktika/ res2dinv. pdf $>$. Acesso em: 21 mai. 2008.

MATOS, B.A. Avaliação da ocorrência e do transporte de microrganismo no aqüifero freático do cemitério de Vila Nova Cachoeirinha, município de São Paulo. 2001. 113 f. Tese (Doutorado em Recursos Minerais e Hidrogeologia) - Escola Politécnica da USP, São Paulo, 2001.

MIGLIORINI, R.B. Cemitérios como fonte de poluição em aqüiferos: estudo do cemitério Vila Formosa na bacia Sedimentar de São Paulo. 1994. 74 f. Dissertação (Mestrado em Recursos Minerais e Hidrogeologia) - Instituto de Geociências da USP, São Paulo, 1994.
ORELLANA, E. Prospección geoeléctrica en corriente continua. Madrid: Paraninfo, 1972. Biblioteca Técnica Philips.

PACHECO, A. Os cemitérios como risco potencial para as águas de abastecimento. Revista do Sistema de Planejamento e Administração Metropolitana, São Paulo, ano IV, n. 17, p. 25-31, 1986.

PANNATIER, Y. Variowin: software for spatial data analysis in 2D. New York: Springer-Verlag, 1996.

WARD, S.H. Resistivity and polarization methods. In:WARD, S.H. Geotechnical and environmental geophysics. Tulsa: SEG, 1990. v. 3, p. 147-189. 